\title{
Hybrid and parallel extracorporeal membrane oxygenation circuits
}

\author{
Aakash Shah, MD, ${ }^{\mathrm{a}}$ Sagar Dave, DO, ${ }^{\mathrm{b}}$ Corbin E. Goerlich, MD, ${ }^{\mathrm{a}}$ and David J. Kaczorowski, MD ${ }^{\mathrm{a}}$
}

\begin{abstract}
Associate Editor Note-Extracorporeal membrane oxygenation (ECMO) has been around since the 1950s and remains a tool for the management of patients with refractory respiratory or circulatory failure. The authors of this Invited Expert Opinion address modifications to traditional circuitry when peripheral cannulation does not appear sufficient and augmentation of venous drainage or ECMO flow is necessary. Although conversion to central cannulation is one option, expansion of the existing circuit to incorporate either a hybrid approach (eg, transitioning from veno-venous ECMO to veno-arteriovenous ECMO in the setting of refractory hypoxia or declining cardiac function) is another option. The descriptions of the techniques, rationale, physiology, potential pitfalls, and outcome data of each approach should serve as an important and handy reference for surgeons involved in the management of these patients.
\end{abstract}

\section{Abe DeAnda, Jr, MD}

Extracorporeal membrane oxygenation (ECMO) is one type of extracorporeal life support for patients with cardiopulmonary failure. ECMO may serve as a as bridge to recovery, long-term mechanical support, or transplantation. In patients with isolated respiratory failure, veno-venous (VV) ECMO is the preferred modality, whereas in patients with isolated cardiac or combined cardiopulmonary failure, veno-arterial (VA) ECMO is generally the preferred modality. ${ }^{1}$ At many centers, the preferred technique for institution of ECMO is via peripheral vascular access, as opposed to central access, and this is often done percutaneously. Peripheral cannulation can allow rapid institution of ECMO with minimal morbidity. Although in the majority of patients, peripheral ECMO provides adequate support, there are certain instances in which isolated VA or VV ECMO support may not be sufficient. Some of these instances arise from limitations of peripheral ECMO, such as peripheral vessels potentially limiting the size of cannulae,

\footnotetext{
From the ${ }^{\mathrm{a}}$ Division of Cardiac Surgery, Department of Surgery, and ${ }^{\mathrm{b}}$ Program in Trauma, Department of Surgery, University of Maryland School of Medicine, Baltimore, Md.

Received for publication Jan 29, 2021; accepted for publication Feb 3, 2021; available ahead of print Feb 24, 2021.

Address for reprints: David J. Kaczorowski, MD, UPMC Heart and Vascular Institute, 200 Lothrop St., Suite C-720, Pittsburgh, PA 15213 (E-mail: kaczorowskidj2@ upmc.edu).

JTCVS Techniques 2021;8:77-85

2666-2507

Copyright (C) 2021 The Authors. Published by Elsevier Inc. on behalf of The American Association for Thoracic Surgery. This is an open access article under the CC BY-NCND license (http://creativecommons.org/licenses/by-nc-nd/4.0/).

https://doi.org/10.1016/j.xjtc.2021.02.024
}

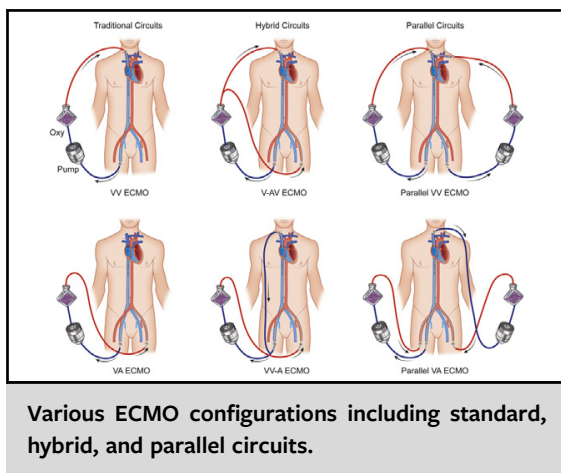

\section{CENTRAL MESSAGE \\ In patients on isolated VV or VA ECMO, conversion to a hybrid or parallel ECMO strategy may prove beneficial if support is insufficient}

See Commentaries on pages 86 and 88.

recirculation of oxygenated blood in VV ECMO, competition with native cardiac output in VA ECMO, and the inability to capture the entire cardiac output. In these situations, modifications or alternative strategy may be required. Before modifying the mechanical support strategy, efforts should be made to manage the situation by optimizing medical management and maximizing the existing platform. This includes the management of refractory hypoxia for patients on VV-ECMO (eg, beta blockade, paralysis, proning, etc) as well as adequate left ventricular decompression for patients on VA ECMO (eg, volume removal, direct left ventricular or left atrial drainage, atrial septostomy, etc).,3

If a change in cannulation strategy is required, conversion to a central cannulation via a full or upper hemisternotomy is one such option. Although this strategy may lead to sufficient support, it is invasive and can result in significant morbidity in an already critically ill patient. In select patients, a less-invasive alternative that may pose less morbidity is reconfiguration of peripheral ECMO to a "hybrid" strategy, with additional peripheral arterial or venous cannulae, which will be the focus of this review.

Patients who are on VV ECMO and have refractory hypoxia or declining cardiac function may require the addition of an arterial return cannula. Alternately, patients who are on VA ECMO and have respiratory failure leading to harlequin syndrome, or North-South syndrome, may require the 
addition of a venous return cannula. ${ }^{4,5}$ In both cases, there is one venous drainage cannula and the return is split between a venous and arterial return, resulting in veno-arteriovenous (V-AV) ECMO. Furthermore, patients on VA ECMO who have insufficient flow for adequate end-organ perfusion may require additional venous drainage cannulas for venoveno-arterial (VV-A) ECMO. Similarly, patients on VV ECMO who have inadequate support due to a high cardiac output that is unable to be captured by one ECMO circuit may require the addition of a parallel ECMO circuit. ${ }^{6}$ Overall, these "hybrid" ECMO strategies represent a small percentage of total patients managed with ECMO. Extracorporeal Life Support Organization registry data show that less than $1 \%$ of adults supported for respiratory or cardiac failure are supported with a hybrid strategy. ${ }^{7}$

While we focus on hybrid and parallel ECMO circuits, there are other modalities and combinations of support not discussed here. One example is the use cannula for left ventricular unloading in the setting of pulmonary edema with peripheral VA-ECMO. These cannulae are usually placed either in the left atrium or directly in the left ventricle and connected to the drainage limb of the ECMO circuit. In addition, percutaneous ventricular assist devices, such as the Impella (Abiomed, Danvers, Mass), can be used in concert with ECMO (eg, placed across the aortic valve for left ventricular unloading with peripheral VA-ECMO, or in concert with VV-ECMO in patients with combined respiratory and cardiac failure if oxygenation is adequate). Also, the recent availability of cannulae, such as the Protek Duo (Cardiac Assist, Pittsburgh, Pa) may be the preferred modality for patients with combined respiratory failure and right ventricular failure, as opposed to a hybrid ECMO strategy.

\section{HYBRID ECMO CIRCUITS Technique}

V-AV ECMO involves venous drainage through a venous cannula and return of blood to both the arterial and venous side of the circulation after gas exchange through the

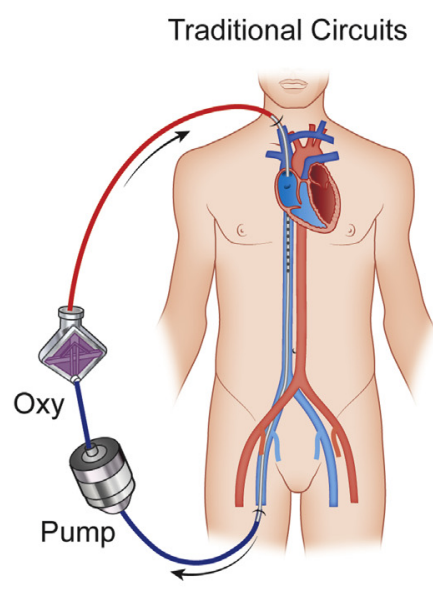

W ECMO

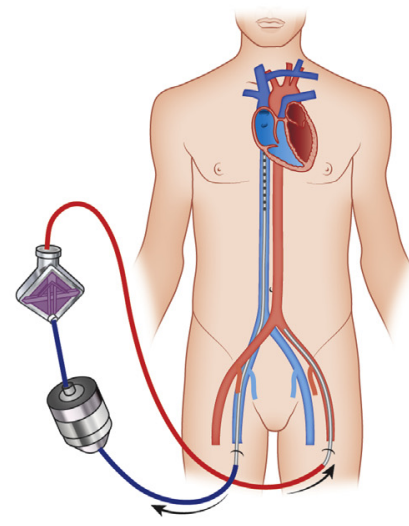

VA ECMO
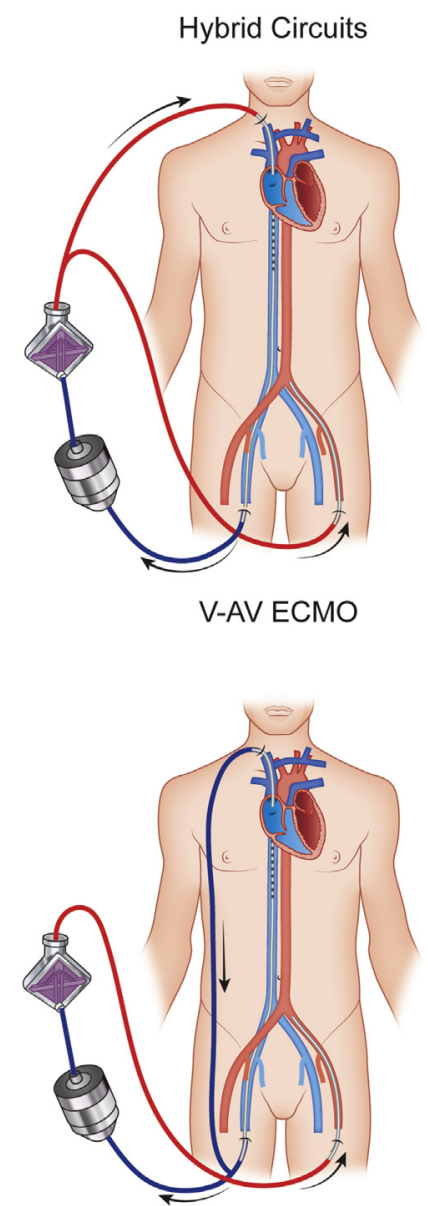

V-A ECMO
Parallel Circuits
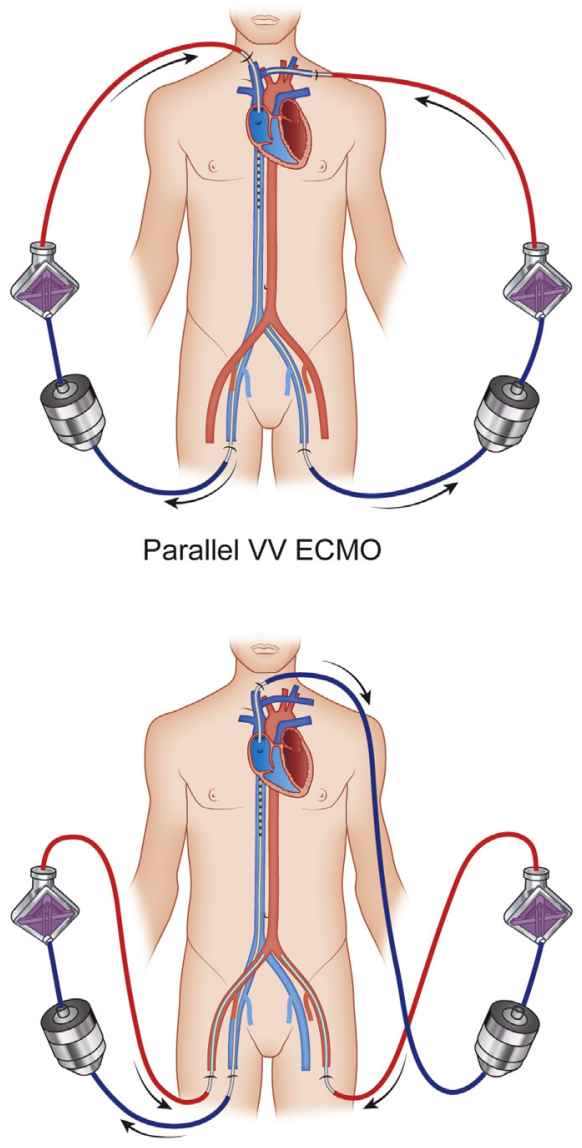

Parallel VA ECMO

FIGURE 1. Various extracorporeal membrane oxygenation configurations including standard, hybrid and parallel circuits. $O x y$, Oxygen; $V V E C M O$, venovenous extracorporeal membrane oxygenation; $V$ - $A V E C M O$, veno-arteriovenous extracorporeal membrane oxygenation; $V A E C M O$, venoarterial extracorporeal membrane oxygenation; $V V-A E C M O$, venoveno-arterial extracorporeal membrane oxygenation. 
oxygenator. In patients already supported by VV ECMO, an arterial return cannula can be added to the circuit either via the femoral arteries or axillary arteries, which allows for circulatory support in the setting of cardiovascular collapse. In patients on VA ECMO, a venous return cannula can be added to the circuit either via the right internal jugular vein or the femoral veins, allowing for the return of oxygenated blood to the right circulatory system and can be helpful in the setting of harlequin syndrome. ${ }^{4}$ Access and positioning of the cannula is no different from positioning a venous return cannula in a patient supported on isolated VV ECMO, or an arterial return cannula in a patient support on isolated VA ECMO, respectively (Figure 1). In either case, the cannula is connected to the existing ECMO circuit with a Y-connector from the return limb of the circuit. Generally, our practice has been to use percutaneous cannula insertion under ultrasound guidance with the use of bedside transthoracic echocardiography to confirm and optimize cannula position. These techniques are applied for conversion to hybrid strategies as well. Complications of cannula insertion include vascular or cardiac injuries from the wire, dilator, or cannula insertion, as well as arrhythmias. The use of fluoroscopy or transesophageal echocardiography may help mitigate these complications. After insertion, cannula position can be monitored with routine radiographs and echocardiography (Figure 2).

VV-A ECMO requires 2 or more drainage cannulae in a circuit. An additional venous drainage cannula can be added to the circuit via the right internal jugular vein, being the preferred site assuming the patient has an existing femoral venous cannula. The contralateral femoral vein could also be used but would result in 2 cannulae in the inferior vena cava. The left subclavian vein is another alternative but is not easily compressed if there is a vascular injury. The additional drainage cannula should be positioned so as not to significantly overlap with existing drainage cannula in the circuit and connected to the existing ECMO circuit with a $y$-connector from the drainage limb of the circuit. The added cannula often provides $0.5-1 \mathrm{~L} / \mathrm{min}$ of additional flow to the existing circuit and may be suitable for patients who have ongoing end-organ malperfusion due to insufficient VA ECMO flows. While this can allow for increased capture of the patient's native cardiac output to improve the ECMO flow fraction in patients with harlequin

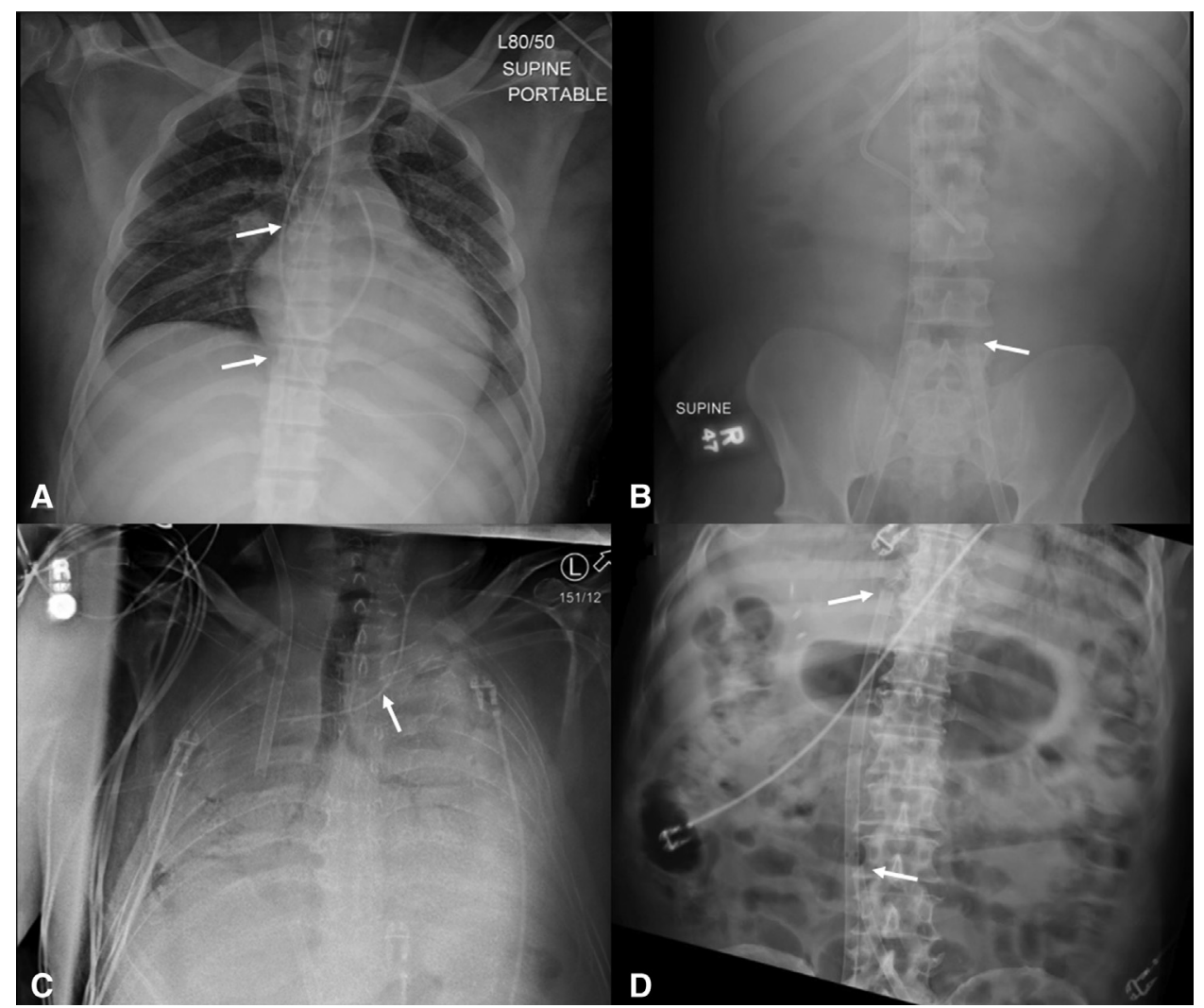

FIGURE 2. Radiographs of patients with various hybrid cannulation strategies. A, Chest radiograph showing right internal jugular venous cannula right femoral venous cannula optimal positioning (white arrows) in a patient on V-AV ECMO. B, Abdominal radiograph showing left femoral arterial cannula positioning (white arrow) in the same patient on V-AV ECMO. C, Chest radiograph showing positioning of left subclavian venous cannula (white arrow) for additional drainage in a patient on VV ECMO. D, Abdominal radiograph showing positioning of bilateral venous drainage cannulae (white arrows) in a patient on VV ECMO. 
syndrome, it may not be sufficient to treat profound upper body hypoxia, and in this case V-AV ECMO may be a better choice.

\section{Flow Diversion}

When blood flow is split between 2 cannulae via a Y-connector on either the drainage or return limb of the circuit, consideration must be given to the flow through each cannula. In VV-A ECMO, the flow distribution between venous drainage cannulae may be equivalent (depending on the caliber and position of the cannula), given similar resistance in the venous drainage system and single arterial return pressure. However, the flow distribution between the arterial and venous return limbs can be significantly different in V-AV ECMO, given the difference in the pressure head from the venous system and arterial systems. Zhao and colleagues ${ }^{8}$ showed in a sheep model that in the setting of harlequin syndrome, as little as $10 \%$ of total flow going through the venous return can result in a measurable improvement in left ventricular oxygen tension, and with $30 \%$ of flow diverted to the venous return the mean left ventricular saturation improves from $74 \%$ to $94 \%$. Similarly, Lee and colleagues ${ }^{9}$ varied the flow differential in 10 patients on intraoperative V-AV ECMO support during lung transplantation and monitored the arterial oxygen concentration and saturation in the ascending aorta. Mean saturation increased from $81 \%$ to $99 \%$ when flow was increased from 0 to $1.5 \mathrm{~L} / \mathrm{min}$ through the venous return limb. The use of an additional flow probe to monitor the flow distribution is useful for maintaining the desired goals (Figure E1, A); however, limiting flow through one cannula compared with the other may lead to hemolysis or thrombosis, which can have catastrophic consequences such as hypoxia, lack of hemodynamic support, and cardiopulmonary collapse. Maintaining flow greater than 1.5 to $2 \mathrm{~L} /$ min can minimize thrombus formation. ${ }^{1,10}$

Blood will preferentially flow toward the path of least resistance. In the case of V-AV ECMO, this is the venous return cannula. The resistance to the venous return cannula must be increased in order to balance the proportion of blood that is returned via each cannula. One strategy to do this is to use a smaller French cannula for the venous return than the arterial return. In addition, smaller tubing for venous limb (eg, 1/4 inch instead of 3/8 inch) allows for limiting flow in the venous return and augmenting arterial flow based on Poiseuille law. However, doing so may limit the size of venous cannula to $14 \mathrm{Fr}^{10}$ Belliato and colleagues $^{10}$ compared combinations of various venous and arterial cannulae and found that use of a $17-\mathrm{Fr} / 18$ $\mathrm{cm}$ arterial cannula and a $17-\mathrm{Fr} / 50-\mathrm{cm}$ venous cannula provided equivalent flows at a total flow of $4.3 \mathrm{~L} / \mathrm{min}$. This represented an intersecting point, where at lower total flows the venous return exceeds the arterial return, and at greater total flows the arterial return exceeds the venous return. ${ }^{10}$

A throttle valve may also be used on the tubing between the Y-connector and the venous return cannula (Figure E1, $B)$. Biscotti and colleagues ${ }^{11}$ described in their experience with 21 patients supported with hybrid ECMO the use of a Hoffman clamp to divert flow. Cakici and colleagues ${ }^{12}$ used a Stockert flow sensor and distributor in 12 cases of hybrid ECMO. Initially patients received 70\% (+/-4.6\%) of the total flow through the venous return cannula. After the occluder was applied, flow through the venous return decreased to $34.3 \%(+/-7.4 \%)$. Although throttle valves can allow for precise adjustment of flow distribution, they can lead to turbulent flow and have potential for hemolysis in the long term. ${ }^{4,6,10,13}$ Without a throttle valve, if a larger venous cannula is used compared with an arterial cannula, flows will consistently be greater in venous compared with arterial return up to $7 \mathrm{~L} / \mathrm{min}$ total flow. ${ }^{10}$

Regardless of the method of flow distribution, hybrid ECMO circuits require close daily monitoring and although anticoagulation goals in hybrid ECMO have not been well studied, these strategies may require an increased anticoagulation goal in comparison with baseline to prevent thrombus formation in areas of lower flow. ${ }^{10}$

\section{Current Reported Experience With Hybrid ECMO}

There have been various case series describing the experience with hybrid ECMO configuration with a total of 77 adult patients (Table 1). The most commonly used techniques for cannulae configuration are femoral venous drainage, femoral arterial return, and internal jugular venous return. Various other configurations have been used with combinations of dual lumen venous cannula, other femoral approaches, and upper extremity arterial cannulae (Table E1). Outcomes from patients supported with hybrid ECMO are varied. Stöhr and colleagues ${ }^{14}$ performed a univariate analysis that showed a trend toward improved outcomes in patients with acute respiratory distress syndrome supported with V-AV ECMO compared with isolated VA and VV ECMO. Mortality reported in literature ranges from $27 \%$ to $61 \%{ }^{11,15,16}$ The authors point out that in many cases, patients were initially supported with VV or VA ECMO then quickly transitioned to hybrid ECMO out of necessity. Variability in outcome data among reports may be attributed to both differences in patient characteristics and unique approaches to caring for patients undergoing hybrid ECMO at different centers.

\section{PARALLEL CIRCUITS \\ Technique}

In some settings, the flow limitations of a single ECMO circuit may prove insufficient for adequate support. This 
TABLE 1. Hybrid circuit case series

\begin{tabular}{|c|c|c|c|c|c|}
\hline \multirow[b]{2}{*}{ Study variables } & \multicolumn{5}{|c|}{ Study, $\mathbf{y}$} \\
\hline & $\begin{array}{c}\text { Stöhr } \\
\text { et al, 2011 }\end{array}$ & $\begin{array}{c}\text { Biscotti } \\
\text { et al, 2014 }\end{array}$ & Ius et al, $2015^{15}$ & $\begin{array}{c}\text { Werner } \\
\text { et al, 2016 }\end{array}$ & $\begin{array}{c}\text { Cakici } \\
\text { et al, } 2017^{12}\end{array}$ \\
\hline No. of adult patients on V-AV & 11 & 21 & 10 & 23 & 12 \\
\hline $\begin{array}{l}\text { Initial cannulation strategy: VA/ } \\
\text { VV/V-AV }\end{array}$ & $3 / 5 / 3$ & $2 / 8 / 11$ & $1 / 9 / 0$ & $7 / 6 / 10$ & $9 / 3 / 0$ \\
\hline ECPR & 0 & 7 & 1 & 9 & 1 \\
\hline $\begin{array}{l}\text { Cannulation site (LE arterial and } \\
\text { UE venous return) }\end{array}$ & N/A & $16(76 \%)$ & $10(100 \%)$ & $18(78 \%)$ & $12(100 \%)$ \\
\hline Age, y & N/A & $44.2 \pm 13.7$ & $56 \pm 12$ & $40.4 \pm 14.7$ & $61.5 \pm 3.5$ \\
\hline Male & N/A & $8(38 \%)$ & $4(40 \%)$ & $14(61 \%)$ & $8(67 \%)$ \\
\hline BSA, $\mathrm{m}^{2}$ & N/A & N/A & $1.7 \pm 0.2$ & N/A & $1.9 \pm 0.02$ \\
\hline \multicolumn{6}{|l|}{ Etiology of illness } \\
\hline Primary cardiac & N/A & $9(43 \%)$ & 0 & $10(43 \%)$ & $8(66 \%)$ \\
\hline Primary respiratory & N/A & $12(57 \%)$ & $9(90 \%)$ & $6(26 \%)$ & $3(25 \%)$ \\
\hline Sepsis & N/A & 0 & 0 & $3(13 \%)$ & $1(8.3 \%)$ \\
\hline Other & N/A & 0 & $1(10 \%)$ & $4(18 \%)$ & 0 \\
\hline $\begin{array}{l}\text { Reason for conversion to hybrid } \\
\text { ECMO, n }\end{array}$ & 11 & 21 & 10 & 13 & 12 \\
\hline VV with cardiac failure & $1(9 \%)$ & $16(76.1 \%)$ & $9(90 \%)$ & $6(46 \%)$ & $3(25 \%)$ \\
\hline VA with harlequin syndrome & 0 & $1(4.7 \%)$ & $1(10 \%)$ & $5(38 \%)$ & $9(75 \%)$ \\
\hline Refractory hypoxia & $10(91 \%)$ & $2(10 \%)$ & 0 & $2(15 \%)$ & 0 \\
\hline Other & 0 & $2(10 \%)$ & 0 & 0 & 0 \\
\hline Method of flow distribution & N/A & Hoffman clamp & $\begin{array}{l}\text { Unspecified } \\
\text { throttle valve }\end{array}$ & Hoffman clamp & $\begin{array}{c}\text { Stockert flow } \\
\text { occluder device }\end{array}$ \\
\hline \multicolumn{6}{|l|}{ Complications } \\
\hline Neurologic & N/A & 0 & N/A & $3(13 \%)$ & 0 \\
\hline Limb ischemia & N/A & $3(14.2 \%)$ & $2(20 \%)$ & $5(22 \%)$ & 0 \\
\hline DVT/PE & N/A & $2(9.5 \%)$ & 0 & $3(13 \%)$ & $1(8.3 \%)$ \\
\hline Cannula thrombosis & N/A & $2(9.5 \%)$ & 0 & 0 & 0 \\
\hline Hemorrhage & N/A & 9 & $3(30 \%)$ & $4(17 \%)$ & $1(8.3 \%)$ \\
\hline Infection & N/A & 0 & $3(30 \%)$ & $9(39 \%)$ & $3(25 \%)$ \\
\hline \multicolumn{6}{|l|}{ Outcomes } \\
\hline Time with hybrid, $d$ & N/A & N/A & N/A & $4.58(\mathrm{IQR}, 2.63,7.46)$ & $6.4 \pm 1.8$ \\
\hline Time on ECMO, d & $7.53 \pm 7.21$ & $6.5 \pm 5.5$ & $10 \pm 4$ & $5.88(\mathrm{IQR}, 4.04,10.5)$ & N/A \\
\hline Mortality & $27 \%$ & $38.1 \%$ & $50 \%$ & $61 \%$ & $33 \%$ \\
\hline
\end{tabular}

$V$ - $A V$, Veno-arteriovenous; $V A$, venoarterial; $V V$, venovenous; $E C P R$, extracorporeal cardiopulmonary resuscitation; $L E$, lower extremity; $U E$, upper extremity; $N / A$, not available; $B S A$, body surface area; $E C M O$, extracorporeal membrane oxygenation; $D V T$, deep venous thrombosis; $P E$, pulmonary embolism; $I Q R$, interquartile range.

may be observed in patients on VV ECMO for respiratory failure who have an unusually high cardiac output state, as seen in sepsis, for example. The inability of one ECMO circuit to capture an adequate fraction of the cardiac output may result in refractory hypoxia that is resistant to rescue maneuvers (eg, beta-blockade, temperature control, paralysis, and proning). In this setting, an additional drainage and return cannula connected to a separate VV ECMO circuit may provide additional oxygenation. Similarly, in patients on VA ECMO with flows insufficient for adequate end-organ perfusion, an additional VA ECMO circuit may provide additional systemic flow (Figure 1). Finally, as an alternative to V-AV ECMO, a VV and VA
ECMO circuit may be run in parallel in patients with cardiac and pulmonary failure. While in theory this may circumvent the considerations of differential flow in a V-AV ECMO circuit, other approaches, including central ECMO, may be preferable.

\section{Considerations}

Aside from the additional morbidity that is associated with having 4 instead of 2 cannulae, there are several considerations in managing parallel ECMO circuits. In the setting of 2 peripheral VV ECMO circuits, one must consider the potential for recirculation within each circuit, as well as cross-circulation between the 2 circuits when 
TABLE 2. Parallel circuit case reports

\begin{tabular}{|c|c|c|c|}
\hline \multirow[b]{2}{*}{ Study variables } & \multicolumn{3}{|c|}{ Study, y } \\
\hline & Malik et al, $2017^{17}$ & Rosenbaum et al, $2020^{18}$ & Mailman et al, 2016 ${ }^{19}$ \\
\hline Circuit setup & $\begin{array}{l}\text { Dual peripheral VV ECMO } \\
\text { circuits }\end{array}$ & $\begin{array}{c}\text { Dual VV ECMO } \\
\text { (RVAD + oxygenator) } \\
\text { circuits }\end{array}$ & VV and VA ECMO circuits \\
\hline Cannulation sites & $\begin{array}{l}\text { Circuit 1: right CFV drainage, } \\
\text { RIJ return } \\
\text { Circuit 2: left CFV drainage, left } \\
\text { subclavian vein return }\end{array}$ & $\begin{array}{c}\text { Circuit } 1 \text { (central): RA } \\
\text { drainage, PA return } \\
\text { Circuit } 2 \text { (peripheral): dual } \\
\text { lumen cannula with RA } \\
\text { drainage, PA return }\end{array}$ & N/A \\
\hline Age, y & 39 & 26 & 27 \\
\hline Sex & Female & Male & Male \\
\hline Weight, $\mathrm{kg}$ & 55 & 88.4 & N/A \\
\hline $\mathrm{BSA}, \mathrm{m}^{2}$ & 1.6 & 2.03 & N/A \\
\hline Etiology of illness & Intra-abdominal sepsis & $\begin{array}{l}\text { Necrotizing pulmonary } \\
\text { blastomycosis }\end{array}$ & $\begin{array}{l}\text { Bleomycin pulmonary } \\
\text { toxicity }\end{array}$ \\
\hline Reason for parallel circuit & Refractory hypoxemia & $\begin{array}{l}\text { Refractory hypoxemia and } \\
\text { RV failure }\end{array}$ & $\begin{array}{c}\text { Refractory hypoxemia and } \\
\text { RV failure }\end{array}$ \\
\hline Flows before parallel circuit, $\mathrm{L} / \mathrm{min}$ & 5.5 & 4.9 & N/A \\
\hline $\mathrm{PaO}_{2}$ before parallel circuit, $\mathrm{mm} \mathrm{Hg}$ & 40 & 43 & N/A \\
\hline Flows after parallel circuit, $\mathrm{L} / \mathrm{min}$ & $8-9$ & 8.4 & N/A \\
\hline $\mathrm{PaO}_{2}$ after parallel circuit, $\mathrm{mm} \mathrm{Hg}$ & 187 & N/A & N/A \\
\hline Complications & $\begin{array}{l}\text { AKI requiring temporary } \\
\text { hemodialysis, tracheostomy }\end{array}$ & AKI & N/A \\
\hline Days on ECMO (parallel circuit/total) & $14 / 60$ & $119 / 147$ & N/A \\
\hline Outcome & Survival to discharge & $\begin{array}{l}\text { Bridge to heart-lung-kidney } \\
\text { transplant, subsequent death } \\
\text { secondary to sepsis }\end{array}$ & Death on ECMO \\
\hline
\end{tabular}

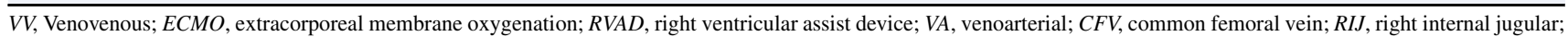
$R A$, right atrium; $P A$, pulmonary artery; $N / A$, not available; $B S A$, body surface area; $R V$, right ventricle; $P a o_{2}$, oxygen tension; $A K I$, acute kidney injury.

positioning the cannulae. There should be an adequate distance between drainage and return cannulae of both circuits, and ideally, the drainage cannula from one circuit should not be proximal to the return cannula of the other circuit.

In the setting with 2 peripheral VA-ECMO circuits, it may be possible to capture the majority of the cardiac output for a patient. Although this has not previously been described, this may lead to a situation in which there is little to no flow through the heart and lungs. Although this is the norm with cardiopulmonary bypass, it may not be ideal for an extended run of ECMO. Long periods of low flow in the setting of standard anticoagulation ranges for ECMO support may lead to thrombus formation within the heart and/or pulmonary circulation, and the authors of this manuscript would not recommend its use under most circumstances.

\section{Data From Case Reports}

At the time of this review, there are only 3 known mentions of parallel ECMO circuits in the literature, all of which were employed in patients who were on ECMO with a septic state (Table 2). Malik and colleagues ${ }^{17}$ reported successfully managing a patient with acute respiratory distress syndrome who had refractory hypoxia with 2 parallel VV ECMO circuits. Parallel circuits were employed, as there was concern that an additional drainage cannula in the existing circuit would be insufficient to capture the patient's cardiac output in the setting of profound hypoxia. Rosenbaum and colleagues ${ }^{18}$ described the use of 2 parallel circuits in a patient respiratory failure due to a necrotizing lung infection and right ventricular failure. Of note, with both drainage cannulae in the right atrium and both return cannulae in the pulmonary artery, these parallel circuits likely have minimal recirculation and cross-circulation. In addition, we would advise particular caution with this configuration in the setting of left ventricular dysfunction, as a right-sided cardiac output exceeding the left-sided cardiac output could lead to pulmonary edema or hemorrhage. Finally, Mailman and colleagues ${ }^{19}$ describe the use of VV and VA ECMO parallel circuits in a patient with bleomycin 
pulmonary toxicity and right ventricular failure, however there is limited information available for this case.

\section{SUMMARY}

Although hybrid and parallel ECMO circuits may prove useful in managing certain patients, generally these strategies should not be used as the initial means of cannulation. Rather, patients should be supported with isolated VA or VV ECMO with the understanding that patient conditions are dynamic and they may require a modification to their modality of support during their course. This may require optimization of the existing circuit, changing cannulation site (eg, femoral artery to axillary artery), conversion from one modality to another, the employment of hybrid or parallel ECMO circuits, or even conversion to central cannulation, and de-escalation from there as the patients' status changes. Further, cannula position should be optimized and medical management should be maximized.

Patients who ultimately require a hybrid or parallel ECMO support represent a small fraction of total patients receiving ECMO, as illustrated by Extracorporeal Life Support Organization data. In general, survival is lower in these patients, with adult respiratory patients having a survival of $32 \%$ with V-AV support compared to $60 \%$ with VV support, and adult cardiac patients having a survival of $32 \%$ with V-AV support compared with $41 \%$ with VA support. ${ }^{7}$ There are currently no data that clearly establish a mortality benefit of the use of hybrid or parallel circuits. The high mortality associated with these strategies likely reflects the severity of illness of patients who require hybrid strategies compared with those who are supported with isolated VV or VA ECMO.

Mechanical circulatory support is a complex landscape, and patients requiring support have dynamic disease processes. With the myriad of ECMO configurations and mechanical circulatory support devices that are available, each patient requires an individualized approach. The determination must be made of the appropriate cannulation strategy for ECMO and whether to use it in isolation or in concert with another circulatory support device to best fit each patient.

\section{Conflict of Interest Statement}

David J. Kaczorowski has a patent for devices for endovascular access through extracorporeal life support circuits. All other authors reported no conflicts of interest.

The Journal policy requires editors and reviewers to disclose conflicts of interest and to decline handling or reviewing manuscripts for which they may have a conflict of interest. The editors and reviewers of this article have no conflicts of interest.

\section{References}

1. Sorokin V, MacLaren G, Vidanapathirana PC, Delnoij T, Lorusso R. Choosing the appropriate configuration and cannulation strategies for extracorporeal membrane oxygenation: the potential dynamic process of organ support and importance of hybrid modes. Eur J Heart Fail. 2017; 19(suppl 2):75-83.

2. Patel B, Arcaro M, Chatterjee S. Bedside troubleshooting during venovenous extracorporeal membrane oxygenation (ECMO). J Thorac Dis. 2019;11(suppl 14):S1698-707.

3. Lindfors M, Frenckner B, Sartipy U, Bjällmark A, Broomé M. Venous cannula positioning in arterial deoxygenation during veno-arterial extracorporeal membrane oxygenation - a simulation study and case report. Artif Organs. 2017;41: $75-81$.

4. Brasseur A, Scolletta S, Lorusso R, Taccone FS. Hybrid extracorporeal membrane oxygenation. J Thorac Dis. 2018;10(suppl 5):S707-15.

5. Napp LC, Kühn C, Hoeper MM, Vogel-Claussen J, Haverich A, Schäfer A, et al. Cannulation strategies for percutaneous extracorporeal membrane oxygenation in adults. Clin Res Cardiol. 2016;105:283-96.

6. Camboni D, Philip A, Schmid C, Loforte A. Double, triple and quadruple cannulation for veno-arterial extracorporeal membrane oxygenation support: is there a limit? Ann Cardiothorac Surg. 2019;8:151-9.

7. Thiagarajan RR, Barbaro RP, Rycus PT, Mcmullan DM, Conrad SA, Fortenberry JD, et al. Extracorporeal life support organization registry international report 2016. ASAIO J. 2017;63:60-7.

8. Zhao J, Wang D, Ballard-Croft C, Wang J, Hsu PL, Bacchetta M, et al. Hybrid extracorporeal membrane oxygenation using Avalon elite double lumen cannula ensures adequate heart/brain oxygen supply. Ann Thorac Surg. 2017; 104:847-53

9. Lee JG, Kim N, Narm KS, Suh JW, Hwang J, Paik HC, et al. The effect of additional stepwise venous inflow on differential hypoxia of veno-arterial extracorporeal membrane oxygenation. ASAIO J. 2020;66:803-8.

10. Belliato M, Caneva L, Aina A, Degani A, Mongodi S, Prahl Wittberg L, et al. An experimental model of veno-venous arterial extracorporeal membrane oxygenation. Int J Artif Organs. 2020;43:268-76.

11. Biscotti M, Lee A, Basner RC, Agerstrand C, Abrams D, Brodie D, et al. Hybrid configurations via percutaneous access for extracorporeal membrane oxygenation: a single-center experience. ASAIO J. 2014;60:635-42.

12. Cakici M, Gumus F, Ozcinar E, Baran C, Bermede O, Inan MB, et al. Controlled flow diversion in hybrid venoarterial-venous extracorporeal membrane oxygenation. Interact Cardiovasc Thorac Surg. 2018;26:112-8.

13. Fraser KH, Zhang T, Taskin ME, Griffith BP, Wu ZJ. A quantitative comparison of mechanical blood damage parameters in rotary ventricular assist devices: shear stress, exposure time and hemolysis index. J Biomech Eng. 2012;134 081002 .

14. Stöhr F, Emmert MY, Lachat ML, Stocker R, Maggiorini M, Falk V, et al. Extracorporeal membrane oxygenation for acute respiratory distress syndrome: is the configuration mode an important predictor for the outcome? Interact Cardiovasc Thorac Surg. 2011;12:676-80.

15. Ius F, Sommer W, Tudorache I, Avsar M, Siemeni T, Salman J, et al. Veno-venoarterial extracorporeal membrane oxygenation for respiratory failure with severe haemodynamic impairment: technique and early outcomes. Interact Cardiovasc Thorac Surg. 2015;20:761-7.

16. Werner NL, Coughlin M, Cooley E, Haft JW, Hirschl RB, Bartlett RH, et al. The University of Michigan experience with veno-venoarterial hybrid mode of extracorporeal membrane oxygenation. ASAIO J. 2016;62:578-83.

17. Malik A, Shears LL, Zubkus D, Kaczorowski DJ. Parallel circuits for refractory hypoxemia on venovenous extracorporeal membrane oxygenation. J Thorac Cardiovasc Surg. 2017;153:e49-51.

18. Rosenbaum AN, Bohman JK, Rehfeldt KH, Stulak JM, Daly RC, Klompas AM, et al. Dual RVAD-ECMO circuits to treat cardiogenic shock and hypoxemia due to necrotizing lung infection: a case report. A A Pract. 2020;14:e01181.

19. Mailman J, Levine A. 1603: shunting into trouble: a case of severe bleomycin toxicity requiring dual ECMO circuits. Crit Care Med. 2016;44:476.

Key Words: extra-corporeal membrane oxygenation, extracorporeal life support, respiratory failure, cardiogenic shock, mechanical circulatory support 


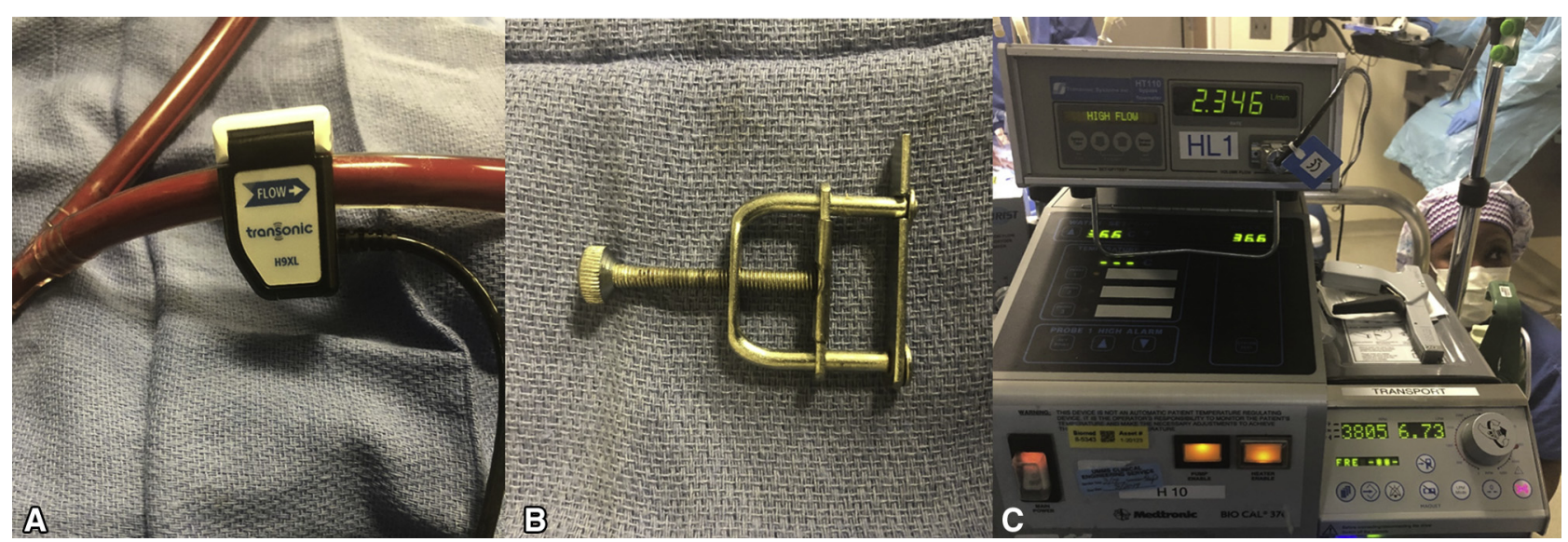

FIGURE E1. A, Additional flow probe to monitor flow distribution between the venous and arterial return. B, Hoffman clamp, which can be used as a throttle valve for managing flow distribution. C, Flow readings, which show a total ECMO circuit flow of $6.73 \mathrm{~L} / \mathrm{min}$ and a flow of $2.35 \mathrm{~L} / \mathrm{min}$ to the venous return, which equates to a 35:65 split of flow to the venous and arterial returns respectively. 
TABLE E1. Frequency of cannula sites in veno-arteriovenous extracorporeal membrane oxygenation case series ${ }^{11,12,15,16}$

\begin{tabular}{lccr}
\hline & Venous drainage cannula & Arterial return cannula & Venous return cannula \\
\hline Common femoral vein & $58(88 \%)$ & - & $1(2 \%)$ \\
Internal jugular vein & & & - \\
$\quad$ Dual lumen cannula & $8(12 \%)$ & - & $8(12 \%)$ \\
$\quad$ Single lumen cannula & $0(0 \%)$ & $60(91 \%)$ & $57(86 \%)$ \\
Common femoral artery & - & $6(9 \%)$ & - \\
Right axillary artery & - & - & - \\
\hline
\end{tabular}

